\title{
Teor de nitrogênio inorgânico no solo em função de plantas de cobertura, fontes de nitrogênio e inibidor de nitrificação ${ }^{1}$
}

\author{
Edemar Moro ${ }^{2}$, Carlos Alexandre Costa $\mathrm{Crusciol}^{3}$, Adriano Stephan Nascente ${ }^{4}$, Heitor Cantarella ${ }^{5}$
}

\begin{abstract}
Soil inorganic nitrogen content according to cover crops, nitrogen sources and nitrification inhibitor

The use of cover crops can change the soil $\mathrm{NO}_{3}$ : $\mathrm{NH}_{4}^{+}$ratio, providing larger amounts of $\mathrm{NH}_{4}^{+}$, and enable the development of crops which absorb more or prefer this form of nitrogen $(\mathrm{N})$, like rice. This study aimed at evaluating the effect of the interaction of cover crops and $\mathrm{N}$ sources, with and without nitrification inhibitor (dicyandiamide), under no-tillage system (NTS). The experiment was carried out in 2009/2010, in Botucatu, São Paulo State, Brazil, in an Oxisol under NTS for six years. The experimental design was randomized blocks, arranged in a split plot, with four replications. The plots consisted of six cover crops species (Urochloa brizantha, U. decumbens, $U$. humidicola, $U$. ruziziensis, Pennisetum americanum and Crotalaria spectabilis) and the split plots were seven forms of nitrogen fertilization, at 0 and 30 days after the emergence (DAE) of rice $[1$ - control, without $\mathrm{N}$ fertilization; 2 - calcium nitrate $\left(40+40 \mathrm{~kg} \mathrm{ha}^{-1}\right) ; 3$ - calcium nitrate $\left(0+80 \mathrm{~kg} \mathrm{ha}^{-1}\right) ; 4$ - ammonium sulfate $\left(40+40 \mathrm{kgha}^{-1}\right) ; 5$ - ammonium sulfate $\left(0+80 \mathrm{~kg} \mathrm{ha}^{-1}\right)$; 6 - ammonium sulfate + dicyandiamide $\left(40+40 \mathrm{~kg} \mathrm{ha}^{-1}\right)$; and 7 - ammonium sulfate + dicyandiamide $\left.\left(0+80 \mathrm{~kg} \mathrm{ha}^{-1}\right)\right]$. The use of nitrification inhibitor and the $C$. spectabilis cover crop resulted in higher levels of ammonium in the soil. The application of the ammonium source without nitrification inhibitor in a total dose at $30 \mathrm{DAE}$ and with inhibitor (split or total dose) resulted in the highest levels of nitrate in the soil.
\end{abstract}

KEY-WORDS: Urochloa spp.; no-tillage system; leaching.

\section{INTRODUÇÃO}

O sistema plantio direto (SPD) possibilita uma série de benefícios, como o aumento da atividade biológica do solo, redução da erosão e maior ciclagem de nutrientes (Aranda et al. 2011). Neste sistema, é

\section{RESUMO}

A utilização de plantas de cobertura pode alterar a relação $\mathrm{NO}_{3}^{-}: \mathrm{NH}_{4}^{+}$no solo, proporcionando maiores quantidades de $\mathrm{NH}_{4}^{+}$e podendo viabilizar o desenvolvimento de culturas que absorvem mais e preferem esta forma de nitrogênio $(\mathrm{N})$, como o arroz. Objetivou-se avaliar a influência da interação de plantas de cobertura e fontes de $\mathrm{N}$, com e sem inibidor de nitrificação (dicianodiamida), em sistema plantio direto (SPD). O experimento foi realizado em 2009/2010, em Botucatu (SP), em Latossolo Vermelho distroférrico cultivado por seis anos no SPD. O delineamento experimental foi em blocos casualizados, em esquema de parcela subdividida, com quatro repetições. As parcelas foram constituídas por seis espécies de plantas de cobertura do solo (Urochloa brizantha, U. decumbens, $U$. humidicola, $U$. ruziziensis, Pennisetum americanum e Crotalaria spectabilis) e as subparcelas por sete formas de fertilização nitrogenada, aos 0 e 30 dias após a emergência (DAE) do arroz [1 - controle, sem aplicação de nitrogênio; 2 - nitrato de cálcio $\left(40+40 \mathrm{~kg} \mathrm{ha}^{-1}\right) ; 3$ - nitrato de cálcio $\left(0+80 \mathrm{~kg} \mathrm{ha}^{-1}\right)$; 4 - sulfato de amônio $\left(40+40 \mathrm{~kg} \mathrm{ha}^{-1}\right) ; 5$ - sulfato de amônio $\left(0+80 \mathrm{~kg} \mathrm{ha}^{-1}\right) ; 6$ - sulfato de amônio + dicianodiamida $\left(40+40 \mathrm{~kg} \mathrm{ha}^{-1}\right)$; e 7 - sulfato de amônio + dicianodiamida $\left.\left(0+80 \mathrm{~kg} \mathrm{ha}^{-1}\right)\right]$. O uso do inibidor de nitrificação e o cultivo de C. spectabilis proporcionaram maiores teores de amônio no solo. A aplicação da fonte amoniacal sem inibidor em dose total aos 30 DAE e com inibidor tanto parcelada quanto em dose total proporcionaram os maiores teores de nitrato no solo.

PALAVRAS-CHAVE: Urochloa spp.; sistema plantio direto; lixiviação.

fundamental a formação de uma cobertura vegetal na superfície do solo, antes da implantação da cultura principal (Nascente \& Crusciol 2012).

Como os resíduos produzidos por culturas comerciais, geralmente, são insuficientes para uma adequada cobertura do solo, faz-se necessário intro-

1. Trabalho recebido em mar./2013 e aceito para publicação em nov./2013 ( $\mathrm{n}^{\circ}$ registro: PAT 22907).

2. Universidade do Oeste Paulista (Unoeste), Departamento de Agronomia, Presidente Prudente, SP, Brasil. E-mail: edemar@unoeste.br.

3. Universidade Estadual Paulista (Unesp), Faculdade de Ciências Agronômicas, Departamento de Produção Vegetal, Botucatu, SP, Brasil.E-mail: crusciol@fca.unesp.br.

4. Empresa Brasileira de Pesquisa Agropecuária (Embrapa Arroz e Feijão), Santo Antônio de Goiás, GO, Brasil. E-mail: adriano.nascente@embrapa.br.

5. Instituto Agronômico de Campinas (IAC), Centro de Solos e Recursos Ambientais, Campinas, SP, Brasil. E-mail: cantarella@iac.sp.gov.br. 
duzir plantas capazes de produzir grande quantidade de massa, no outono/inverno, de modo que o solo permaneça coberto o maior tempo possível, para a implantação da próxima cultura de verão (Pacheco et al. 2011, Nascente et al. 2013a).

Dessa forma, um importante fator a ser considerado é a decomposição de resíduos das culturas de cobertura, que pode alterar, significativamente, os teores de nutrientes no solo (Carvalho et al. 2011, Nascente et al. 2013b). Neste sentido, merece destaque o nitrogênio $(\mathrm{N})$, cujos compostos reagem rapidamente no solo, sendo, portanto, um dos nutrientes mais dinâmicos no SPD (D'Andrea et al. 2004, Nascente et al. 2011). A maior parte do N (mais de 90\%) está na fração orgânica do solo, a qual constitui um grande reservatório de formas mais prontamente disponíveis, como a nítrica e a amoniacal. Estas formas minerais, apesar de representarem pequena parcela do $\mathrm{N}$ total, são de extrema importância, do ponto de vista nutricional, já que são elas as absorvidas pelos vegetais e micro-organismos (Fageria et al. 2011).

O conhecimento das quantidades de nitrogênio liberadas pelas plantas de cobertura é fundamental para que elas possam ser efetivamente incorporadas ao sistema de produção agrícola (Silva et al. 2008). Segundo Nascente et al. (2012), a produção de palha pelas plantas de cobertura na entressafra e o manejo do nitrogênio estão entre as principais dificuldades encontradas pelos produtores que usam o SPD. Adicionalmente, Pacheco et al. (2011) relatam que uma das características primordiais para a seleção de espécies de cobertura do solo é a capacidade de acumular $\mathrm{N}$ na massa da matéria seca, com sua posterior liberação, para ser utilizada pela cultura posterior.

A maioria das plantas absorve indistintamente nitrato e amônio, não tendo dificuldades em se desenvolver em ambientes ricos em nitrato, como os solos aeróbicos (Malavolta 1980). Entretanto, existem plantas que preferem, no início do seu desenvolvimento, o nitrogênio na forma amoniacal, como o arroz (Nascente et al. 2013d). No entanto, no SPD, as quantidades de nitrato são ainda maiores do que nos sistemas com revolvimento do solo. Experimentos desenvolvidos por Sá (1999), D’Andrea et al. (2004) e Nascente et al. (2013c) permitiram constatar que, no SPD, há maior disponibilidade de $\mathrm{N}_{-} \mathrm{NO}_{3}{ }^{-}$no solo, em relação ao sistema com revolvimento, devido ao fato de o ambiente no SPD possuir mais umidade e maior teor de nutrientes e quantidade de matéria orgânica, favorecendo a atividade microbiológica, em especial de bactérias nitrificadoras.

A utilização de plantas de cobertura pode alterar essa relação, proporcionando maiores quantidades de amônio no solo e podendo viabilizar o desenvolvimento de culturas que absorvem mais e preferem esta forma de $\mathrm{N}$, como o arroz (Malavolta 1980, Holzschuh et al. 2009). Uma alternativa para o cultivo de plantas de cobertura é o milheto, já bastante utilizado em safrinha, para a produção de palhada no SPD (Crusciol et al. 2011, Pacheco et al. 2011), e as braquiárias, pela elevada produção de massa de matéria seca (Kluthcouski et al. 2000, Nascente et al. 2012). Além disto, o uso de leguminosas pode incrementar os teores de nutrientes no solo, principalmente o nitrogênio, via fixação biológica (Silva et al. 2008).

Outra alternativa para retardar a oxidação do amônio a nitrato no solo seria a utilização de inibidores sintéticos de nitrificação. Existem numerosos compostos registrados como inibidores de nitrificação, sendo os principais a nitrapirina, dicianodiamida (DCD) e 3,4-dimetil pirazol fosfato (DMPP) (Subbarao et al. 2009). O DCD retarda a primeira fase da nitrificação, desativando as enzimas das bactérias que convertem as formas de $\mathrm{N}$ amoniacais em nítrica, resultando em significativa redução na lixiviação de $\mathrm{NO}_{3}^{-}$(Marcelino 2009). A vantagem do uso do DCD é o menor custo, em relação a outros inibidores como a nitrapirina, e a alta solubilidade em água, possibilitando que seja aplicado de forma líquida, além de ser menos volátil que a nitrapirina, se decompor em $\mathrm{NH}_{4}^{+}$e CO no solo e ser classificado como substância não tóxica (Di \& Cameron 2002).

Marcelino (2009) observou redução de 76\% na oxidação do amônio a nitrato, em ureia tratada com DCD, 15 dias após a incubação do fertilizante ao solo. Entretanto, apesar dos resultados positivos obtidos com inibidores sintéticos, estes produtos ainda não foram amplamente adotados como ferramenta tecnológica, havendo dúvidas, em relação ao seu custo $\mathrm{x}$ benefício. Estas dúvidas surgem pela falta de consistência dos resultados, nos diversos ambientes agroclimáticos e diferentes tipos de solo (Subbarao et al. 2007).

Adicionalmente, constata-se que existem poucos trabalhos apresentando o efeito combinado de plantas de cobertura e fontes de N, nas formas inorgânicas no solo. Assim, objetivou-se avaliar a influência da interação de plantas de cobertura e 
fontes de $\mathrm{N}$, com e sem inibidor de nitrificação, nas formas minerais de $\mathrm{N}$ no solo em SPD.

\section{MATERIAL E MÉTODOS}

O experimento foi realizado no ano agrícola 2009/2010, na Fazenda Experimental Lageado da Faculdade de Ciências Agronômicas da Universidade Estadual Paulista (Unesp), em Botucatu (SP), em uma área que foi cultivada com arroz (Oryza sativa) (22051'S, 48 $26^{\prime}$ 'W e $740 \mathrm{~m}$ de altitude). Segundo a classificação climática de Köppen, o clima predominante na região é do tipo Cwa, tropical de altitude, com inverno seco e verão quente e chuvoso.

O solo da área experimental é classificado como Nitossolo Vermelho distroférrico, sendo manejado sob SPD há seis anos. A sequência de culturas, neste período, foi a seguinte: soja/aveia preta, milho/ Urochloa brizantha, milho/U. brizantha, soja/aveia branca, feijão/aveia branca, soja/pousio, milho verão/ instalação do experimento.

O delineamento experimental foi em blocos casualizados, no esquema de parcela subdividida, com quatro repetições. As parcelas foram constituídas por seis espécies de plantas de cobertura do solo (U. brizantha cv. Marandu, $U$. decumbens, $U$. humidicola, $U$. ruziziensis, Pennisetum americanum - milheto e Crotalaria spectabilis) e as subparcelas (unidade experimental) por sete formas de fertilização nitrogenada, aos 0 e 30 dias após a emergência (DAE) do arroz [ 1 - controle, sem aplicação de nitrogênio; 2 - nitrato de cálcio $\left(40+40 \mathrm{~kg} \mathrm{ha}^{-1}\right) ; 3$ - nitrato de cálcio $\left(0+80 \mathrm{~kg} \mathrm{ha}^{-1}\right)$; 4 - sulfato de amônio $\left(40+40 \mathrm{~kg} \mathrm{ha}^{-1}\right) ; 5$ - sulfato de amônio $\left(0+80 \mathrm{~kg} \mathrm{ha}^{-1}\right) ; 6$ - sulfato de amônio + dicianodiamida (DCD) $\left(40+40 \mathrm{~kg} \mathrm{ha}^{-1}\right) ; \mathrm{e} 7$ - sulfato de amônio + DCD $\left.\left(0+80 \mathrm{~kg} \mathrm{ha}^{-1}\right)\right]$. As dimensões de cada unidade experimental eram de 7,0 $\mathrm{m}$ de comprimento por 4,5 m de largura.

Antes da implantação do experimento, foi realizada a caracterização química do solo, à profundidade de $0-20 \mathrm{~cm}$, e os valores obtidos foram: matéria orgânica $=34 \mathrm{~g} \mathrm{dm}^{-3} ; \mathrm{pH}\left(\mathrm{CaCl}_{2}\right)=$

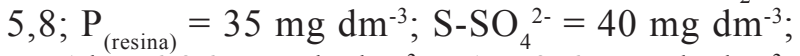
$\mathrm{H}+\mathrm{Al}=6,36 \mathrm{mmol}_{\mathrm{c}} \mathrm{dm}^{-3} ; \mathrm{K}^{+}=3,6 \mathrm{mmol}_{\mathrm{c}} \mathrm{dm}^{-3}$; $\mathrm{Ca}^{2+}=43,0 \mathrm{mmol}_{\mathrm{c}} \mathrm{dm}^{-3} ; \mathrm{Mg}^{2+}=34,0 \mathrm{mmol}_{\mathrm{c}} \mathrm{dm}^{-3}$; $\mathrm{V}=73 \% ; \mathrm{Fe}=6,0 \mathrm{mg} \mathrm{dm}^{-3} ; \mathrm{Cu}=7,5 \mathrm{mg} \mathrm{dm}^{-3}$; $\mathrm{Mn}=105 \mathrm{mg} \mathrm{dm}^{-3} ; \mathrm{Zn}=2,3 \mathrm{mg} \mathrm{dm}^{-3} ; \mathrm{B}=$ $0,22 \mathrm{mg} \mathrm{dm}^{-3} ; \mathrm{N}^{-N_{4}}{ }^{+}=6,05 \mathrm{mg} \mathrm{dm}^{-3} ;{\mathrm{e} \mathrm{N}-\mathrm{NO}_{3}}^{-}=$ $15,7 \mathrm{mg} \mathrm{dm}^{-3}$.
A dessecação da vegetação espontânea foi realizada com o herbicida glyphosate, na dose de $2.000 \mathrm{~g} \mathrm{ha}^{-1}$ de equivalente ácido (e.a.), sete dias antes da semeadura. A densidade de semeadura para Pennisetum americanum foi de $20 \mathrm{~kg} \mathrm{ha}^{-1}$, para Crotalaria spectabilis de $12 \mathrm{~kg}$ de semente ha $\mathrm{h}^{-1} \mathrm{e}$ para as espécies de Urochloa de $10 \mathrm{~kg} \mathrm{ha}^{-1}$ de sementes, com valor cultural de $40 \%$. O espaçamento utilizado, para todas as espécies, foi de $17 \mathrm{~cm}$ entre as linhas, com semeadura de grãos miúdos à profundidade de 3,0 cm. Em outubro de 2009, aos 150 DAE, as plantas de cobertura foram dessecadas com glyphosate (2.000 $\mathrm{g} \mathrm{ha}^{-1}$ do e.a.). Neste momento, foi feita a determinação da produção de massa seca destas plantas de cobertura.

O arroz (cultivar IAC 202) foi semeado em dezembro de 2009, com semeadora-adubadora (modelo Personalle Drill 13 Semeato para SPD). O espaçamento foi de $0,34 \mathrm{~m}$ entre as linhas e a densidade de semeadura de 80 sementes $\mathrm{m}^{-1}$. A adubação de semeadura foi realizada com $100 \mathrm{~kg} \mathrm{ha}^{-1}$ da fórmula 00-20-20 (Cantarella \& Furlani 1996). As fontes de $\mathrm{N}$ foram aplicadas imediatamente após a emergência das plântulas de arroz e aos 30 DAE. O adubo foi distribuído em filete contínuo, sobre a superfície do solo, a aproximadamente $10 \mathrm{~cm}$ da linha de semeadura. A DCD foi previamente misturada às fontes amoniacais, no dia da aplicação, na concentração de $10 \%$, em relação ao teor de $\mathrm{N}$ do fertilizante (Trenkel 1997). Durante o período de desenvolvimento das plantas, foram realizadas as práticas agrícolas necessárias.

Antes da dessecação, foi determinada a produção de massa seca das plantas de cobertura. No solo, foram determinados os valores de $\mathrm{pH}\left(\mathrm{CaCl}_{2}\right)$ e os

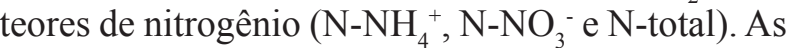
amostras foram coletadas às profundidades de $0-5 \mathrm{~cm}$ e 5-20 cm, aos 14, 28 e 42 DAE do arroz (Silva 1999). Os dados foram submetidos à análise de variância e as médias comparadas pelo teste LSD $(p \leq 0,05)$.

\section{RESULTADOS E DISCUSSÃO}

A produção de massa seca das plantas de cobertura amostradas antes da dessecação foi a seguinte: $P$. americanum $=10,7 \mathrm{tha}^{-1}, C$. spectabilis $=$ $8,7 \mathrm{t} \mathrm{ha}^{-1}$, U. brizantha cv. Marandu $=12,5 \mathrm{t} \mathrm{ha}^{-1}$, $U$. decumbens $=14,6 \mathrm{tha}^{-1}, U$. humidicola $=12,5 \mathrm{tha}^{-1}$ e $U$. ruziziensis $=7,0 \mathrm{t} \mathrm{ha}^{-1}$. Segundo Nascente et al. (2013a, 2013b), as culturas de cobertura são conhecidas por produzirem grande quantidade de 
biomassa, sendo esta característica muito importante, para locais como a região do Cerrado, que apresenta baixa fertilidade do solo. As culturas de cobertura, durante o processo de degradação da palha, liberam nutrientes, o que pode proporcionar aumento na fertilidade do solo.

Os valores de $\mathrm{pH}$ do solo, aos 14 DAE do arroz, foram influenciados pelo manejo da fertilização nitrogenada. Na camada de $0-5 \mathrm{~cm}$, a fonte amoniacal sem inibidor provocou reduções significativas no $\mathrm{pH}$ do solo, nas parcelas cultivadas com quatro $(C$. spectabilis, $U$. brizantha, $U$. decumbens e $U$. ruziziensis) das seis espécies de cobertura utilizadas (Tabela 1). A reação de nitrificação, comum em solos aeróbicos, libera íons de hidrogênio, que acidificam o solo (Malavolta 1980).

Com base nos resultados, pode-se inferir que as plantas de cobertura afetaram diferentemente o $\mathrm{pH}$ do solo. Além disto, este resultado demonstrou que o inibidor possivelmente reduziu a nitrificação, não causando reduções significativas do $\mathrm{pH}$, como observado na fonte amoniacal sem inibidor e relatado por outros autores (Marcelino 2009, Subbarao et al. 2009). Outro fator que poderia afetar este resultado seria o alto teor de nitrato existente no solo, no início do experimento.

$\mathrm{Na}$ camada de 5-20 cm, a fonte amoniacal sem inibidor causou redução no $\mathrm{pH}$ do solo, quando cultivadas as plantas de cobertura $C$. spectabilis e $B$. decumbens, sendo que, para as demais fontes de nitrogênio, os valores de $\mathrm{pH}$ não diferiram (Tabela 1). Este resultado pode ser reflexo das características intrínsecas de cada espécie, como o sistema radicular e as características do material orgânico produzido, que afetam diferentemente as características do solo. Resultados semelhantes foram relatados por Guimarães et al. (2003) e Moreti et al. (2007), que observaram alterações significativas no $\mathrm{pH}$ do solo, causadas por plantas de cobertura. Eles acrescentam que as plantas podem exsudar ácidos de suas raízes para o solo e afetar, significativamente, o seu pH (Moreti et al. 2007).

Analisando-se a média dos valores de $\mathrm{pH}$, em relação a cada planta de cobertura, e a forma de manejo da adubação nitrogenada, verificou-se que, à profundidade de $0-5 \mathrm{~cm}$, não houve efeito significativo. À profundidade de $5-20 \mathrm{~cm}$, houve efeito das plantas de cobertura, sendo que o milheto proporcionou o menor valor de $\mathrm{pH}$, diferindo da U. humidicola (Tabela 1). Segundo Coneglian \&
Moraes (2006), os resíduos de plantas de cobertura utilizadas no SPD podem alterar o $\mathrm{pH}$, sendo relatada redução significativa no $\mathrm{pH}$ do solo $(4,8$ para 4,6$)$, à profundidade de $10-20 \mathrm{~cm}$, em condições de ausência e presença de milheto.

$\mathrm{Na}$ avaliação realizada aos $28 \mathrm{DAE}$ do arroz, observou-se que os valores de $\mathrm{pH}$ do solo também foram influenciados pelo manejo da adubação nitrogenada e pelas plantas de cobertura (Tabela 1).

$\mathrm{Na}$ camada de $0-5 \mathrm{~cm}$ de profundidade, a fonte amoniacal provocou reduções significativas dos valores em três das seis parcelas cultivadas com plantas de cobertura (C. spectabilis, U. brizantha e $U$. decumbens), diferindo da fonte nítrica, o que pode ser reflexo da qualidade da matéria orgânica produzida por estas plantas de cobertura, que interagiram significativamente com a adubação nitrogenada, como relatado por Guimarães et al. (2003) e Moreti et al. (2007).

Na camada de 5-20 cm, a redução do pH ocorreu em quatro das seis parcelas cultivadas com plantas de cobertura. A adição de inibidor de nitrificação à fonte amoniacal não proporcionou diferenças significativas no $\mathrm{pH}$, em relação ao tratamento controle e à fonte nítrica (Tabela 1). A única exceção foram as parcelas com $U$. humidicola. Estes resultados demonstram que o inibidor atuou de forma a manter o nitrogênio por mais tempo na forma amoniacal, uma vez que a oxidação do $\mathrm{NH}_{4}^{+}$libera hidrogênio, reduzindo o $\mathrm{pH}$.

O maior valor de $\mathrm{pH}$ no solo, com a $U$. humidicola, pode estar relacionado ao seu efeito na inibição da nitrificação e ao uso de DCD, pois esta espécie de braquiária produz um diterpeno cíclico, denominado "brachialactone" (Subbarao et al. 2009), que pode bloquear o caminho das enzimas amônia mono-oxigenase (AMO) e hidroxilamina oxidoredutase (HAO), presentes nas bactérias Nitrosomonas (N.) europaea (Subbarao et al. 2007).

Nas avaliações realizadas aos 42 DAE do arroz, verificou-se que, na camada de $0-5 \mathrm{~cm}$, os maiores valores de $\mathrm{pH}$ foram observados no controle e para a fonte nítrica, independentemente da forma como foi manejada, diferindo, estatisticamente, das demais fontes (Tabela 1). Assim, observaram-se os mesmos resultados para as três avaliações e, da mesma forma, foram observados menores valores de $\mathrm{pH}$, nos tratamentos em que o $\mathrm{N}$ foi aplicado na forma amoniacal, o que pode ser reflexo do processo de nitrificação, no qual ocorre liberação de hidro- 
Tabela 1. Valores de $\mathrm{pH}\left(\mathrm{CaCl}_{2}\right)$ do solo, em função do manejo da adubação nitrogenada e plantas de cobertura, no sistema plantio direto (Botucatu, SP, 2010).

\begin{tabular}{|c|c|c|c|c|c|c|c|c|}
\hline \multirow{2}{*}{$\begin{array}{l}\text { Manejo do } \\
\text { nitrogênio }\end{array}$} & \multirow{2}{*}{$\begin{array}{l}\text { Profundidade } \\
\text { (cm) }\end{array}$} & \multicolumn{6}{|c|}{ Plantas de cobertura } & \multirow{2}{*}{ Média } \\
\hline & & MILH & CROT & BRIZ & DECU & HUMI & RUZI & \\
\hline & & & & & $14 D A E$ & & & \\
\hline Controle & \multirow{4}{*}{$0-5$} & $5,6 \mathrm{aAB}$ & $5,5 \mathrm{aB}$ & $5,7 \mathrm{aAB}$ & $5,9 \mathrm{aA}$ & $5,7 \mathrm{aAB}$ & $5,6 \mathrm{aAB}$ & $5,7 \mathrm{a}$ \\
\hline NO - 40 & & $5,5 \mathrm{aA}$ & $5,5 \mathrm{aA}$ & $5,7 \mathrm{aA}$ & $5,7 \mathrm{aA}$ & $5,7 \mathrm{aA}$ & $5,6 \mathrm{aA}$ & $5,6 \mathrm{a}$ \\
\hline $\mathrm{NH}-40$ & & $5,6 \mathrm{aA}$ & $4,9 \mathrm{bC}$ & $5,2 \mathrm{bBC}$ & $5,1 \mathrm{bBC}$ & $5,5 \mathrm{aAB}$ & $5,2 \mathrm{bBC}$ & $5,3 \mathrm{~b}$ \\
\hline NHI - 40 & & $5,5 \mathrm{aA}$ & $5,7 \mathrm{aA}$ & $5,7 \mathrm{aA}$ & $5,6 \mathrm{aA}$ & $5,6 \mathrm{aA}$ & $5,5 \mathrm{abA}$ & $5,6 \mathrm{a}$ \\
\hline Média & & $5,6 \mathrm{~A}$ & $5,4 \mathrm{~A}$ & $5,6 \mathrm{~A}$ & $5,6 \mathrm{~A}$ & $5,6 \mathrm{~A}$ & $5,5 \mathrm{~A}$ & - \\
\hline Controle & \multirow{4}{*}{$5-20$} & $4,4 \mathrm{aA}$ & $4,5 \mathrm{aA}$ & $4,7 \mathrm{abA}$ & $4,6 \mathrm{aA}$ & $4,6 \mathrm{aA}$ & $4,5 \mathrm{aA}$ & $4,6 \mathrm{a}$ \\
\hline $\mathrm{NO}-40$ & & $4,5 \mathrm{aA}$ & $4,8 \mathrm{aA}$ & $4,8 \mathrm{aA}$ & $4,6 \mathrm{aA}$ & $4,7 \mathrm{aA}$ & $4,7 \mathrm{aA}$ & $4,7 \mathrm{a}$ \\
\hline $\mathrm{NH}-40$ & & $4,5 \mathrm{aAB}$ & $4,1 \mathrm{bC}$ & $4,4 \mathrm{bABC}$ & $4,3 \mathrm{aBC}$ & $4,7 \mathrm{aA}$ & $4,4 \mathrm{aABC}$ & $4,4 \mathrm{~b}$ \\
\hline NHI - 40 & & $4,2 \mathrm{aB}$ & $4,7 \mathrm{aA}$ & $4,6 \mathrm{abA}$ & $4,5 \mathrm{aAB}$ & $4,7 \mathrm{aA}$ & $4,6 \mathrm{aA}$ & $4,6 \mathrm{a}$ \\
\hline \multirow[t]{2}{*}{ Média } & & $4,4 \mathrm{~B}$ & $4,5 \mathrm{AB}$ & $4,6 \mathrm{AB}$ & $4,5 \mathrm{AB}$ & $4,7 \mathrm{~A}$ & $4,6 \mathrm{AB}$ & - \\
\hline & \multirow{5}{*}{$0-5$} & & & & $28 D A E$ & & & \\
\hline Controle & & $5,4 \mathrm{aB}$ & $5,6 \mathrm{aAB}$ & $5,9 \mathrm{aA}$ & $5,6 \mathrm{aAB}$ & $5,8 \mathrm{aA}$ & $5,3 \mathrm{bB}$ & $5,6 \mathrm{a}$ \\
\hline NO - 40 & & $5,2 \mathrm{aBC}$ & $5,5 \mathrm{aAB}$ & $5,6 \mathrm{abAB}$ & $5,1 \mathrm{bC}$ & $5,7 \mathrm{aA}$ & $5,8 \mathrm{aA}$ & $5,5 \mathrm{a}$ \\
\hline $\mathrm{NH}-40$ & & $5,6 \mathrm{aA}$ & $4,9 \mathrm{bC}$ & $5,3 \mathrm{bAB}$ & $5,0 \mathrm{bBC}$ & $5,7 \mathrm{aA}$ & $5,7 \mathrm{abA}$ & $5,4 \mathrm{a}$ \\
\hline NHI - 40 & & $4,8 \mathrm{bC}$ & $5,7 \mathrm{aA}$ & $5,7 \mathrm{abA}$ & $5,3 \mathrm{abB}$ & $5,8 \mathrm{aA}$ & $5,4 \mathrm{abAB}$ & $5,5 \mathrm{a}$ \\
\hline Média & & $5,3 \mathrm{C}$ & $5,4 \mathrm{BC}$ & $5,6 \mathrm{AB}$ & $5,3 \mathrm{C}$ & $5,8 \mathrm{~A}$ & $5,6 \mathrm{AB}$ & - \\
\hline Controle & \multirow{4}{*}{$5-20$} & $4,3 \mathrm{aB}$ & $4,3 \mathrm{abB}$ & $4,5 \mathrm{aAB}$ & $4,6 \mathrm{aAB}$ & $4,7 \mathrm{bA}$ & $4,3 \mathrm{bAB}$ & $4,5 \mathrm{ab}$ \\
\hline NO - 40 & & $4,4 \mathrm{aABC}$ & 4,4 abBC & $4,5 \mathrm{aABC}$ & 4,2 abC & $4,8 \mathrm{bA}$ & $4,7 \mathrm{aAB}$ & $4,5 \mathrm{ab}$ \\
\hline $\mathrm{NH}-40$ & & 4,4 aAB & $4,1 \mathrm{bB}$ & $4,3 \mathrm{aAB}$ & 4,1 bB & $4,7 \mathrm{bA}$ & $4,2 \mathrm{bB}$ & $4,3 \mathrm{~b}$ \\
\hline NHI - 40 & & 4,3 aB & $4,5 \mathrm{aB}$ & $4,5 \mathrm{aB}$ & 4,4 abB & $5,2 \mathrm{aA}$ & 4,4 abB & $4,6 \mathrm{a}$ \\
\hline \multirow[t]{2}{*}{ Média } & & $4,4 \mathrm{~B}$ & $4,3 \mathrm{~B}$ & $4,5 \mathrm{~B}$ & $4,3 \mathrm{~B}$ & $4,9 \mathrm{~A}$ & $4,4 \mathrm{~B}$ & - \\
\hline & \multirow{8}{*}{$0-5$} & & & & $42 D A E$ & & & \\
\hline Controle & & $5,6 \mathrm{aB}$ & $5,6 \mathrm{aB}$ & $5,7 \mathrm{abAB}$ & $5,6 \mathrm{aB}$ & $6,0 \mathrm{aA}$ & $5,4 \mathrm{bB}$ & $5,7 \mathrm{a}$ \\
\hline $\mathrm{NO}-40+40$ & & 5,6 aAB & $5,4 \mathrm{abB}$ & 5,6 abAB & 5,4 abB & 5,6 abAB & $5,7 \mathrm{aA}$ & $5,6 \mathrm{a}$ \\
\hline $\mathrm{NO}-00+80$ & & $5,7 \mathrm{aAB}$ & $5,2 \mathrm{bcC}$ & $5,8 \mathrm{aA}$ & $5,4 \mathrm{abC}$ & 5,7 abAB & $5,4 \mathrm{bC}$ & $5,5 \mathrm{a}$ \\
\hline $\mathrm{NH}-40+40$ & & $5,0 \mathrm{bB}$ & $4,5 \mathrm{dC}$ & $5,0 \mathrm{cB}$ & $4,9 \mathrm{cB}$ & $5,4 \mathrm{cA}$ & $5,3 \mathrm{bA}$ & $5,0 \mathrm{c}$ \\
\hline $\mathrm{NH}-00+80$ & & $5,0 \mathrm{bBC}$ & $4,9 \mathrm{cC}$ & $5,6 \mathrm{abA}$ & $5,3 \mathrm{abAB}$ & $5,5 \mathrm{bcA}$ & $5,6 \mathrm{abA}$ & $5,3 \mathrm{~b}$ \\
\hline $\mathrm{NHI}-40+40$ & & $4,4 \mathrm{cC}$ & $5,3 \mathrm{abAB}$ & $5,4 \mathrm{abAB}$ & $5,1 \mathrm{bcB}$ & $5,5 \mathrm{bcA}$ & $5,4 \mathrm{bAB}$ & $5,2 \mathrm{bc}$ \\
\hline $\mathrm{NHI}-00+80$ & & $4,6 \mathrm{cC}$ & $5,1 \mathrm{bcB}$ & $5,7 \mathrm{abA}$ & $5,2 \mathrm{bcB}$ & $5,7 \mathrm{abA}$ & $5,3 \mathrm{bB}$ & $5,3 \mathrm{bc}$ \\
\hline Média & & $5,1 \mathrm{C}$ & $5,1 \mathrm{C}$ & $5,5 \mathrm{~A}$ & $5,3 \mathrm{BC}$ & $5,6 \mathrm{~A}$ & $5,4 \mathrm{AB}$ & - \\
\hline Controle & \multirow{7}{*}{$5-20$} & $4,5 \mathrm{bcAB}$ & 4,6 abAB & $4,5 \mathrm{abAB}$ & $4,7 \mathrm{aB}$ & $5,1 \mathrm{aA}$ & $4,2 \mathrm{cC}$ & $4,6 \mathrm{ab}$ \\
\hline $\mathrm{NO}-40+40$ & & 4,8 abAB & 4,6 abB & $5,0 \mathrm{aA}$ & 4,4 abC & 4,8 abAB & $4,8 \mathrm{abAB}$ & $4,7 \mathrm{a}$ \\
\hline $\mathrm{NO}-00+80$ & & $4,8 \mathrm{abA}$ & $4,3 \mathrm{bB}$ & $4,5 \mathrm{abAB}$ & 4,6 aAB & $4,6 \mathrm{bAB}$ & $4,8 \mathrm{abA}$ & $4,6 \mathrm{ab}$ \\
\hline $\mathrm{NH}-40+40$ & & $5,0 \mathrm{aA}$ & $4,5 \mathrm{abBC}$ & 4,5 abBC & 4,4 abC & 4,8 abAB & 4,7 abABC & $4,7 \mathrm{a}$ \\
\hline $\mathrm{NH}-00+80$ & & $4,5 \mathrm{bcBC}$ & 4,4 abBC & $4,2 \mathrm{cC}$ & $4,5 \mathrm{abBC}$ & $4,6 \mathrm{bAB}$ & $5,0 \mathrm{aA}$ & $4,5 \mathrm{~b}$ \\
\hline $\mathrm{NHI}-40+40$ & & $4,1 \mathrm{dC}$ & 4,5 abAB & $4,6 \mathrm{abA}$ & $4,2 \mathrm{bBC}$ & $4,8 \mathrm{abA}$ & $4,6 \mathrm{bcA}$ & $4,5 \mathrm{~b}$ \\
\hline $\mathrm{NHI}-00+80$ & & $4,4 \mathrm{cdBC}$ & $4,7 \mathrm{aAB}$ & $4,7 \mathrm{bAB}$ & $4,6 \mathrm{aAB}$ & $4,8 \mathrm{abA}$ & $4,2 \mathrm{cC}$ & $4,6 \mathrm{ab}$ \\
\hline Média & & $4,6 \mathrm{AB}$ & $4,5 \mathrm{~B}$ & $4,6 \mathrm{AB}$ & $4,5 \mathrm{~B}$ & $4,8 \mathrm{~A}$ & $4,6 \mathrm{AB}$ & - \\
\hline
\end{tabular}

MILH - Pennisetum americanum; CROT - Crotalaria spectabilis; BRIZ - Urochloa brizantha; DECU - U. decumbens; HUMI - U. humidicola; RUZI - U. ruziziensis; controle - sem aplicação de N; NO - nitrato de cálcio; NH - sulfato de amônio; NHI - sulfato de amônio + inibidor de nitrificação (DCD); 40 + 40 - 40 kg ha-1 de nitrogênio aplicados aos 0 dias após a emergência (DAE) do arroz e $40 \mathrm{~kg} \mathrm{ha}^{-1}$ aos $30 \mathrm{DAE} ; 00+80$ - $80 \mathrm{~kg}^{-1}$ de nitrogênio aplicados aos 30 DAE. Médias com a mesma letra, minúscula nas colunas e maiúscula nas linhas, não diferem pelo teste $\operatorname{LSD}(\mathrm{p} \leq 0,05)$.

gênio, com efeito direto no $\mathrm{pH}$ do solo (Fageria et al. 2011).

Na camada de 5-20 cm, as formas de manejo do $\mathrm{N}$ praticamente não alteraram os valores de $\mathrm{pH}$ do solo. Este resultado pode ser reflexo do sistema de manejo do solo utilizado, uma vez que, no SPD, devido à presença de palhada na superfície do solo, ocorre maior atividade metabólica, nos primeiros centímetros do solo (D'Andréa et al. 2004). Analisando-se o desdobramento das plantas de cobertura, para cada fonte de $\mathrm{N}$, o efeito mais expressivo foi o maior valor do $\mathrm{pH}$ obtido nas parcelas cultivadas com $U$. humidicola, como constatado nas avaliações anteriores (Tabela 1).

O teor de amônio no solo foi influenciado pelas plantas de cobertura e pelo manejo da adubação 
nitrogenada (Tabela 2). Na camada de $0-5 \mathrm{~cm}$, aos 14 DAE do arroz, a fonte amoniacal com inibidor de nitrificação proporcionou os maiores valores de $\mathrm{NH}_{4}^{+}$no solo de todas as parcelas cultivadas com as plantas de cobertura, sendo que o valor médio obtido com esta fonte (sulfato de amônio + DCD) foi de $20,2 \mathrm{mg} \mathrm{kg}^{-1}$, diferindo, estatisticamente, dos demais tratamentos (fontes de N). Na camada de $5-20 \mathrm{~cm}$, os maiores valores também foram observados quando se utilizou o inibidor de nitrificação.

Crusciol et al. (2011) também observaram aumento nos teores de amônio no solo, após a adubação nitrogenada com fonte amoniacal. Os autores relataram que esta característica é esperada, uma vez que

Tabela 2. Teores de amônio do solo $\left(\mathrm{mg} \mathrm{kg}^{-1}\right)$, em função do manejo da adubação nitrogenada e plantas de cobertura, no sistema plantio direto (Botucatu, SP, 2010).

\begin{tabular}{|c|c|c|c|c|c|c|c|c|}
\hline \multirow{2}{*}{$\begin{array}{l}\text { Manejo do } \\
\text { nitrogênio }\end{array}$} & \multirow{2}{*}{$\begin{array}{l}\text { Profundidade } \\
\text { (cm) }\end{array}$} & \multicolumn{6}{|c|}{ Plantas de cobertura } & \multirow{2}{*}{ Média } \\
\hline & & MILH & CROT & BRIZ & DECU & HUMI & RUZI & \\
\hline & & & & & $14 D A E$ & & & \\
\hline Controle & \multirow{4}{*}{$0-5$} & $13,2 \mathrm{bA}$ & $10,3 \mathrm{bC}$ & $13,7 \mathrm{bA}$ & $10,9 \mathrm{cBC}$ & $12,7 \mathrm{cAB}$ & $10,5 \mathrm{cC}$ & $11,9 \mathrm{c}$ \\
\hline $\mathrm{NO}-40$ & & $10,3 \mathrm{cD}$ & $10,8 \mathrm{bCD}$ & $16,5 \mathrm{aA}$ & $12,7 \mathrm{bcBC}$ & $14,2 \mathrm{bcB}$ & $13,0 \mathrm{bB}$ & $12,9 \mathrm{bc}$ \\
\hline NH - 40 & & $13,3 \mathrm{bABC}$ & $12,1 \mathrm{bC}$ & $13,9 \mathrm{bABC}$ & $14,6 \mathrm{bAB}$ & $14,8 \mathrm{bA}$ & $12,8 \mathrm{bBC}$ & $13,6 \mathrm{~b}$ \\
\hline NHI - 40 & & $23,6 \mathrm{aA}$ & $23,5 \mathrm{aA}$ & $14,7 \mathrm{abD}$ & $20,2 \mathrm{aB}$ & $17,5 \mathrm{aC}$ & $21,7 \mathrm{aAB}$ & $20,2 \mathrm{a}$ \\
\hline Média & & $15,1 \mathrm{~A}$ & $14,2 \mathrm{~A}$ & $14,7 \mathrm{~A}$ & $14,6 \mathrm{~A}$ & $14,8 \mathrm{~A}$ & $14,5 \mathrm{~A}$ & - \\
\hline Controle & \multirow{4}{*}{$5-20$} & $7,5 \mathrm{cD}$ & $9,0 \mathrm{cCD}$ & $9,8 \mathrm{cABC}$ & $11,4 \mathrm{bA}$ & $11,0 \mathrm{abAB}$ & $9,6 \mathrm{bBC}$ & $9,7 \mathrm{~d}$ \\
\hline NO - 40 & & $11,9 \mathrm{bA}$ & $13,2 \mathrm{bA}$ & $11,7 \mathrm{bA}$ & $8,1 \mathrm{cB}$ & $9,4 \mathrm{bB}$ & $9,7 \mathrm{bB}$ & $10,7 \mathrm{c}$ \\
\hline $\mathrm{NH}-40$ & & $12,5 \mathrm{bAB}$ & $13,4 \mathrm{bA}$ & $11,8 \mathrm{bAB}$ & $12,4 \mathrm{bAB}$ & $11,4 \mathrm{aB}$ & $8,6 \mathrm{bC}$ & $11,7 \mathrm{~b}$ \\
\hline NHI - 40 & & $16,8 \mathrm{aAB}$ & $17,0 \mathrm{aA}$ & $15,3 \mathrm{aB}$ & $16,7 \mathrm{aAB}$ & $11,3 \mathrm{aC}$ & $11,8 \mathrm{aC}$ & $14,8 \mathrm{a}$ \\
\hline \multirow[t]{2}{*}{ Média } & & $12,2 \mathrm{~A}$ & $13,2 \mathrm{~A}$ & $12,2 \mathrm{~A}$ & $12,2 \mathrm{~A}$ & $10,8 \mathrm{~B}$ & $9,9 \mathrm{~B}$ & - \\
\hline & \multirow{5}{*}{$0-5$} & & & & $28 D A E$ & & & \\
\hline Controle & & $11,7 \mathrm{aBCD}$ & $10,7 \mathrm{aD}$ & $13,0 \mathrm{bAB}$ & $12,6 \mathrm{bABC}$ & $13,9 \mathrm{aA}$ & $11,2 \mathrm{aCD}$ & $12,2 \mathrm{a}$ \\
\hline NO - 40 & & $11,7 \mathrm{aBC}$ & $11,2 \mathrm{aBC}$ & $14,3 \mathrm{abA}$ & $12,7 \mathrm{bAB}$ & $13,0 \mathrm{abAB}$ & $10,1 \mathrm{aC}$ & $12,2 \mathrm{a}$ \\
\hline $\mathrm{NH}-40$ & & $11,6 \mathrm{aC}$ & $11,0 \mathrm{aC}$ & $13,6 \mathrm{abAB}$ & $15,3 \mathrm{aA}$ & $12,2 \mathrm{abBC}$ & $11,5 \mathrm{aC}$ & $12,5 \mathrm{a}$ \\
\hline NHI - 40 & & $11,4 \mathrm{aB}$ & $11,0 \mathrm{aB}$ & $15,3 \mathrm{aA}$ & $14,2 \mathrm{abA}$ & $12,0 \mathrm{bB}$ & $10,4 \mathrm{aB}$ & $12,4 \mathrm{a}$ \\
\hline Média & & $11,6 \mathrm{BC}$ & $10,9 \mathrm{C}$ & $14,0 \mathrm{~A}$ & $13,7 \mathrm{~A}$ & $12,7 \mathrm{AB}$ & $10,8 \mathrm{C}$ & - \\
\hline Controle & \multirow{4}{*}{$5-20$} & $10,0 \mathrm{aA}$ & $8,2 \mathrm{bB}$ & $10,1 \mathrm{bA}$ & $10,6 \mathrm{bA}$ & $10,9 \mathrm{aA}$ & $10,6 \mathrm{bA}$ & $10,1 \mathrm{~b}$ \\
\hline NO - 40 & & $10,9 \mathrm{aB}$ & $10,3 \mathrm{aBC}$ & $11,4 \mathrm{abB}$ & $8,9 \mathrm{bC}$ & $10,7 \mathrm{aB}$ & $13,1 \mathrm{aA}$ & $11,0 \mathrm{a}$ \\
\hline NH - 40 & & $10,4 \mathrm{aBC}$ & 9,0 abB & $11,8 \mathrm{aB}$ & $13,9 \mathrm{aA}$ & $10,4 \mathrm{aBC}$ & $11,7 \mathrm{abB}$ & $11,2 \mathrm{a}$ \\
\hline NHI - 40 & & $11,4 \mathrm{aA}$ & $10,4 \mathrm{aA}$ & $11,4 \mathrm{abA}$ & $10,4 \mathrm{bA}$ & $11,2 \mathrm{aA}$ & $11,5 \mathrm{abA}$ & $11,1 \mathrm{a}$ \\
\hline \multirow[t]{2}{*}{ Média } & & $10,6 \mathrm{AB}$ & $9,5 \mathrm{~B}$ & $11,2 \mathrm{~A}$ & $11,0 \mathrm{~A}$ & $10,8 \mathrm{~A}$ & $11,7 \mathrm{~A}$ & - \\
\hline & \multirow{8}{*}{$0-5$} & & & & $42 D A E$ & & & \\
\hline Controle & & $12,1 \mathrm{cA}$ & $11,9 \mathrm{dA}$ & $10,7 \mathrm{bA}$ & $10,2 \mathrm{bcA}$ & $12,0 \mathrm{cA}$ & $10,8 \mathrm{cA}$ & $11,3 \mathrm{~d}$ \\
\hline $\mathrm{NO}-40+40$ & & $10,5 \mathrm{cAB}$ & $10,2 \mathrm{~dB}$ & $13,9 \mathrm{bA}$ & $11,6 \mathrm{bcAB}$ & $10,5 \mathrm{cAB}$ & $11,3 \mathrm{cAB}$ & $11,3 \mathrm{~d}$ \\
\hline $\mathrm{NO}-00+80$ & & $12,4 \mathrm{cA}$ & $10,4 \mathrm{dA}$ & $13,7 \mathrm{bA}$ & $12,1 \mathrm{bcA}$ & $10,6 \mathrm{cA}$ & $11,3 \mathrm{cA}$ & $11,8 \mathrm{~d}$ \\
\hline $\mathrm{NH}-40+40$ & & $10,8 \mathrm{c} \mathrm{BC}$ & $13,1 \mathrm{dAB}$ & $13,0 \mathrm{bAB}$ & $8,8 \mathrm{cC}$ & $10,2 \mathrm{cBC}$ & $16,1 \mathrm{bA}$ & $12,0 \mathrm{~d}$ \\
\hline $\mathrm{NH}-00+80$ & & $13,4 \mathrm{cB}$ & $38,8 \mathrm{cA}$ & $13,3 \mathrm{bB}$ & $13,3 \mathrm{bB}$ & $16,7 \mathrm{bB}$ & $13,4 \mathrm{bcB}$ & $18,2 \mathrm{c}$ \\
\hline $\mathrm{NHI}-40+40$ & & $23,6 \mathrm{bB}$ & $54,6 \mathrm{bA}$ & $12,5 \mathrm{bD}$ & $11,1 \mathrm{bcD}$ & $12,1 \mathrm{cD}$ & $16,9 \mathrm{bC}$ & $21,8 \mathrm{~b}$ \\
\hline $\mathrm{NHI}-00+80$ & & $44,6 \mathrm{aC}$ & $59,3 \mathrm{aB}$ & $60,0 \mathrm{aB}$ & $25,5 \mathrm{aD}$ & $22,6 \mathrm{aD}$ & $65,0 \mathrm{aA}$ & $46,2 \mathrm{a}$ \\
\hline Média & & $18,2 \mathrm{C}$ & $28,3 \mathrm{~A}$ & $19,6 \mathrm{AB}$ & $13,2 \mathrm{D}$ & $13,5 \mathrm{D}$ & $20,7 \mathrm{~B}$ & - \\
\hline Controle & \multirow{8}{*}{$5-20$} & $13,0 \mathrm{cA}$ & $11,8 \mathrm{bAB}$ & $10,1 \mathrm{cB}$ & $13,3 \mathrm{abcA}$ & $13,2 \mathrm{abA}$ & $13,9 \mathrm{cA}$ & $12,6 \mathrm{c}$ \\
\hline $\mathrm{NO}-40+40$ & & $12,3 \mathrm{cAB}$ & $12,5 \mathrm{bAB}$ & $11,8 \mathrm{bcB}$ & $11,4 \mathrm{cB}$ & $14,2 \mathrm{abA}$ & $13,5 \mathrm{cAB}$ & $12,6 \mathrm{c}$ \\
\hline $\mathrm{NO}-00+80$ & & $12,4 \mathrm{cAB}$ & $12,7 \mathrm{bAB}$ & $12,9 \mathrm{bAB}$ & $13,6 \mathrm{abcAB}$ & $14,0 \mathrm{abA}$ & $11,6 \mathrm{cB}$ & $12,9 \mathrm{c}$ \\
\hline $\mathrm{NH}-40+40$ & & $12,3 \mathrm{cAB}$ & $12,3 \mathrm{bAB}$ & 12,2 bcAB & $14,3 \mathrm{abA}$ & $11,9 \mathrm{bB}$ & $12,7 \mathrm{cAB}$ & $12,6 \mathrm{c}$ \\
\hline $\mathrm{NH}-00+80$ & & $16,3 \mathrm{aB}$ & $22,5 \mathrm{aA}$ & $12,5 \mathrm{bC}$ & $12,8 \mathrm{abcC}$ & $14,0 \mathrm{abC}$ & $13,6 \mathrm{cC}$ & $15,3 \mathrm{~b}$ \\
\hline NHI - $40+40$ & & $13,7 \mathrm{bcB}$ & $12,2 \mathrm{bB}$ & $12,6 \mathrm{bB}$ & $12,5 \mathrm{bcB}$ & $12,6 \mathrm{bB}$ & $16,6 \mathrm{bA}$ & $13,4 \mathrm{c}$ \\
\hline NHI - $00+80$ & & $15,8 \mathrm{abB}$ & $22,0 \mathrm{aA}$ & $16,3 \mathrm{aB}$ & $15,1 \mathrm{aB}$ & $15,2 \mathrm{aB}$ & $20,0 \mathrm{aA}$ & $17,4 \mathrm{a}$ \\
\hline Média & & $13,7 \mathrm{BC}$ & $15,1 \mathrm{~A}$ & $12,6 \mathrm{C}$ & $13,3 \mathrm{BC}$ & $13,6 \mathrm{BC}$ & $14,6 \mathrm{AB}$ & - \\
\hline
\end{tabular}


ocorre adição de amônio ao solo. Adicionalmente, Malavolta (1980) e Fageria et al. (2011) relataram que os fertilizantes nitrogenados amoniacais são solúveis em água e liberam rapidamente $\mathrm{NH}_{4}^{+}$. Assim, considerando-se a rapidez deste processo, destaca-se o efeito do inibidor de nitrificação (DCD), visto que a coleta do solo foi realizada 14 dias após a aplicação do nitrogênio, no tratamento em que foi aplicada dose única na semeadura, e teores relativamente altos de amônio foram observados nestas parcelas, com a aplicação do inibidor (NHI - 40).

Marcelino (2009) também observou redução na oxidação do amônio a nitrato, em ureia tratada com DCD, 15 dias após a incubação do fertilizante ao solo.

Considerando-se esses resultados, o uso do DCD pode ser uma técnica importante para retardar a nitrificação do $\mathrm{N}$ no solo, no caso de culturas que exigem quantidades equilibradas de nitrato e amônio, principalmente sob SPD, em que a nitrificação é favorecida.

Observando-se o desdobramento dos resultados obtidos para plantas de cobertura, em cada forma de manejo da adubação nitrogenada, constatou-se que houve efeitos significativos. Na camada de $0-5 \mathrm{~cm}$, os teores médios de $\mathrm{NH}_{4}^{+}$não foram influenciados pelas plantas de cobertura (Tabela 2). Na camada de $5-20 \mathrm{~cm}$, os teores médios de $\mathrm{NH}_{4}^{+}$foram menores nas parcelas com B. humidicula e B. ruziziensis. Adicionalmente, de maneira geral, observaram-se maiores teores de amônio nas camadas superficiais, o que pode estar relacionado ao maior acúmulo de matéria orgânica nestas camadas, o que é característico do SPD (Aranda et al. 2011). Outro fator seria o parcelamento da adubação nitrogenada, que proporciona aporte de nitrogênio em dois momentos, ao contrário da dose única, e, também, a aplicação de DCD.

Nas avaliações realizadas aos 28 DAE, verificou-se que as plantas de cobertura e as formas de manejo da adubação nitrogenada provocaram alterações nos teores de $\mathrm{NH}_{4}^{+}$do solo (Tabela 2). $\mathrm{Na}$ camada de 0-5 cm, houve poucas alterações nos teores de amônio, e as médias, em cada forma de manejo, não diferiram, estatisticamente, entre si. Na camada de 5-20 cm, a principal alteração foi observada no controle, cujos teores médios de amônio foram inferiores aos das demais fontes. Assim, com base nestes resultados, supõe-se que parte do amônio das fontes amoniacais passou pelo processo de nitrificação, nos tratamentos em que se aplicou esta fonte de $\mathrm{N}$, razão pela qual não houve diferenças entre a fonte nítrica e as amoniacais. Além disto, o inibidor, provavelmente, não teve mais efeito sobre a nitrificação aos 28 dias após a aplicação, como foi observado aos 14 DAE.

Marcelino (2009), em estudo em vasos, observou que, no tratamento com a maior dose, o inibidor proporcionou, aos 30 dias após a aplicação, inibição de $53 \%$, em relação ao nitrato originado no tratamento com ureia sem DCD. Em condições de campo, o efeito é menos prolongado. Assim, apesar de existir uma série de fatores que afetam o efeito do inibidor, como o clima e o solo, Frye et al. (1989) relatam que, em média, o efeito do DCD na inibição da nitrificação se prolonga apenas por algumas semanas. Mais trabalhos de pesquisa são necessários para identificar os principais fatores que afetam a ação do DCD e a duração do seu efeito nos diferentes ambientes.

Com o desdobramento de plantas de cobertura, em cada forma de manejo do N (Tabela 2), verificou-se que a $U$. brizantha e a $U$. decumbens foram as espécies que proporcionaram os maiores teores de amônio, na camada de 0-5 cm, considerando-se todas as formas de manejo. Na camada de $5-20 \mathrm{~cm}$, o menor e o maior teor médio de amônio $\left(9,5 \mathrm{mg} \mathrm{kg}^{-1}\right.$ e 11,7 $\mathrm{mg} \mathrm{kg}^{-1}$ ) foram observados nas parcelas com C. spectabilis e U. ruziziensis, respectivamente, que diferiram estatisticamente. Os menores teores de amônio observados nas parcelas com o milheto e a crotalária podem estar relacionados à menor quantidade de massa de matéria seca produzida por estas espécies, em relação às espécies do gênero Urochloa, com exceção da U. ruziziensis.

O teor de amônio, aos 42 DAE do arroz, foi influenciado tanto pelas plantas de cobertura como pelas formas de $\mathrm{N}$ (Tabela 2). Na camada de $0-5 \mathrm{~cm}$, os maiores teores de amônio foram observados com a aplicação de $\mathrm{N}$ amoniacal com inibidor na dosagem de $80 \mathrm{~kg} \mathrm{ha}^{-1}$, diferindo dos demais tratamentos. Como a aplicação desta fonte foi realizada aos 30 DAE, em aplicação única, era de se esperar uma maior quantidade desta forma de $\mathrm{N}$ no solo, aos 42 DAE. Entretanto, é importante ressaltar a diferença do resultado $\left(46,2 \mathrm{mg} \mathrm{dm}^{-3}\right)$, em relação à fonte amoniacal sem inibidor de nitrificação $\left(18,2 \mathrm{mg} \mathrm{dm}^{-3}\right)$ que foi aplicada na mesma dose e época. A diferença ocorreu, possivelmente, em virtude do efeito que o DCD exerceu na inibição da nitrificação, mantendo a maior parte do $\mathrm{N}$ na forma amoniacal.

De acordo com Marcelino (2009), os inibidores retardam a formação de $\mathrm{NO}_{3}{ }^{-}$no solo, mediante interferência na atividade das bactérias do gênero 
Nitrosomonas, responsáveis pela oxidação do $\mathrm{NH}_{4}^{+}$ a nitrito $\left(\mathrm{NO}_{2}^{-}\right)$, que corresponde à primeira fase da nitrificação.

$\mathrm{Na}$ camada de 5-20 cm, a aplicação de $80 \mathrm{~kg} \mathrm{ha}^{-1}$ de $\mathrm{N}$ amoniacal, aos 30 DAE, também proporcionou os maiores teores de amônio, principalmente com a adição de DCD (Tabela 2). A alteração no teor de amônio, na camada de $5-20 \mathrm{~cm}$, com o uso do inibidor, foi menor, em relação à camada de $0-5 \mathrm{~cm}$ de profundidade, pois as maiores transformações do $\mathrm{N}$ ocorrem na camada superficial, em razão da intensa atividade microbiana (D'Andréa et al. 2004).

Na camada de $0-5 \mathrm{~cm}$, com o desdobramento das plantas de cobertura, dentro de cada forma de manejo de $\mathrm{N}$, observou-se que a $C$. spectabilis proporcionou os maiores teores de amônio, diferindo, estatisticamente, das demais plantas de cobertura, com exceção da $U$. brizantha (Tabela 2). Este maior teor de amônio nas parcelas com C. spectabilis pode ser explicado pela menor relação $\mathrm{C} / \mathrm{N}$ desta espécie, pois, mesmo não tendo sido avaliada, por ser uma espécie leguminosa, a mineralização da matéria orgânica é mais intensa, sendo o amônio mais rapidamente liberado ao solo (Aita et al. 2007, Aranda et al. 2011), em relação às espécies gramíneas. Os mesmos resultados foram obtidos na camada de $5-20 \mathrm{~cm}$, na qual, com exceção da U. ruziziensis, todas as demais Urochloas apresentaram menores teores de amônio e diferiram da C. spectabilis.

Esses resultados podem estar relacionados à composição química das plantas. De acordo com
Carvalho et al. (2011), plantas de cobertura com menores concentrações de lignina, como a Urochloa ruziziensis e Canavalia brasiliensis, possuem maiores taxas de decomposição de resíduos vegetais. Durante a decomposição das plantas, ocorre liberação de nitrogênio, na forma de amônio.

O teor de nitrato, aos 14 DAE do arroz, na camada de $0-5 \mathrm{~cm}$, foi maior para as fontes amoniacais e menor para o controle (Tabela 3). Os menores teores de nitrato da fonte nítrica, em relação à amoniacal, podem estar associados a perdas de $\mathrm{N}$ por lixiviação, ocasionadas pelas chuvas ocorridas em dezembro de 2009 (Figura 1), no decorrer dos 14 dias da aplicação até a coleta do solo. O nitrato é o elemento mais facilmente perdido por lixiviação (Justino et al. 2006), acompanhando o movimento descendente da água que percola no perfil do solo (Malavolta 1980, Fageria et al. 2011). Além disto, Crusciol et al. (2011) relataram que as cargas dos coloides do solo, normalmente negativas, causam efeito de repulsão às cargas do nitrato, favorecendo sua lixiviação.

Com relação às plantas de cobertura, as parcelas com $U$. brizantha, mesmo com a presença do inibidor, proporcionaram maiores teores de nitrato no solo, independentemente da fonte de N (Tabela 3). Embora tenha ocorrido nitrificação das fontes amoniacais, o uso do inibidor reduziu este efeito nas parcelas cultivadas com C. spectabilis, U. humidicola e $U$. ruziziensis, o que não ocorreu com as demais plantas de cobertura, as quais podem ter sido afeta-

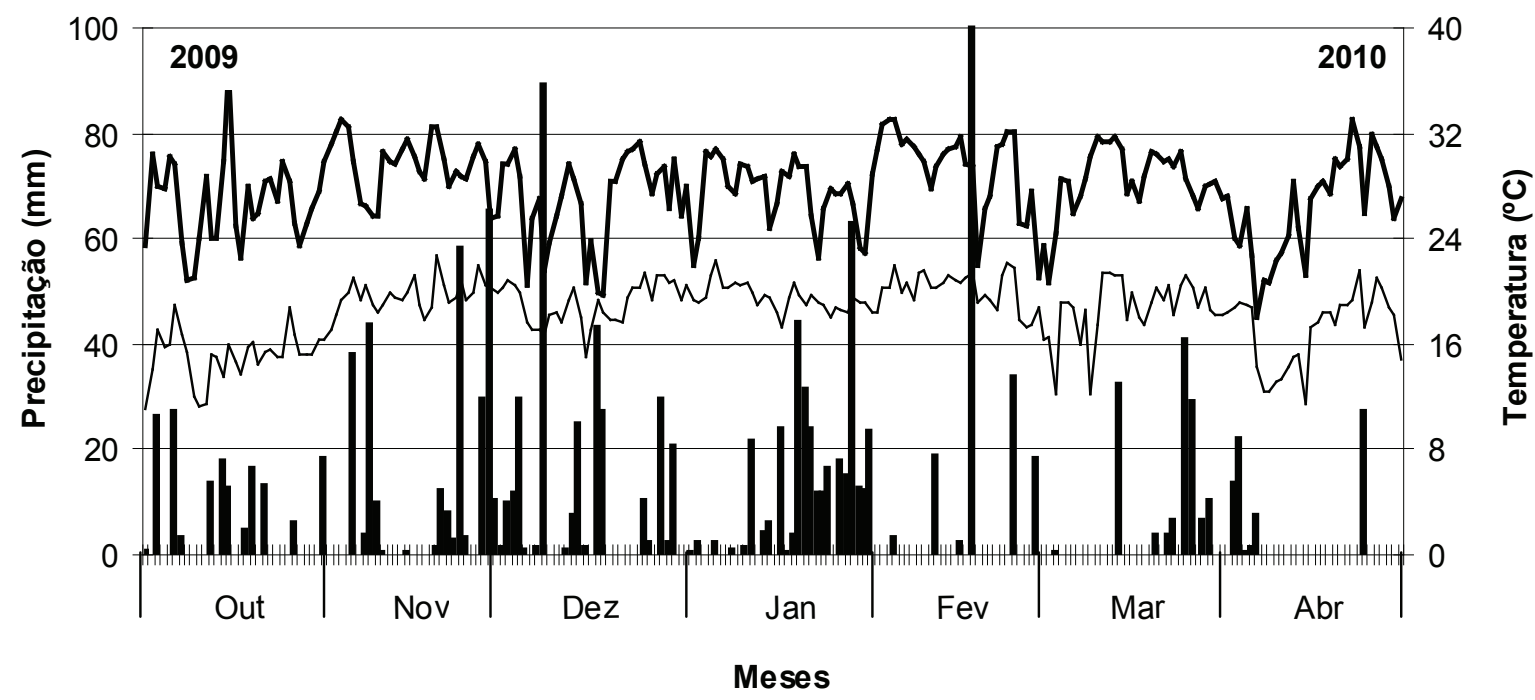

Figura 1. Precipitação (】) e temperaturas máxima (-) e mínima (-) registradas durante a condução do experimento. 
Tabela 3. Teores de nitrato do solo $\left(\mathrm{mg} \mathrm{kg}^{-1}\right)$, em função do manejo da adubação nitrogenada e plantas de cobertura, no sistema plantio direto (Botucatu, SP, 2010).

\begin{tabular}{|c|c|c|c|c|c|c|c|c|}
\hline \multirow{2}{*}{$\begin{array}{l}\text { Manejo do } \\
\text { nitrogênio }\end{array}$} & \multirow{2}{*}{$\begin{array}{l}\text { Profundidade } \\
(\mathrm{cm})\end{array}$} & \multicolumn{6}{|c|}{ Plantas de cobertura } & \multirow{2}{*}{ Média } \\
\hline & & MILH & CROT & BRIZ & DECU & HUMI & RUZI & \\
\hline & & & & & $14 D A E$ & & & \\
\hline Controle & \multirow{4}{*}{$0-5$} & $8,4 \mathrm{cCD}$ & $5,9 \mathrm{dE}$ & $10,4 \mathrm{cBC}$ & $8,2 \mathrm{dD}$ & $13,6 \mathrm{cA}$ & $10,7 \mathrm{~dB}$ & $9,5 \mathrm{~d}$ \\
\hline NO - 40 & & $13,7 \mathrm{bC}$ & $9,5 \mathrm{cD}$ & $21,3 \mathrm{bA}$ & $13,0 \mathrm{cC}$ & $12,0 \mathrm{cC}$ & $17,5 \mathrm{bB}$ & $14,5 \mathrm{c}$ \\
\hline $\mathrm{NH}-40$ & & $24,1 \mathrm{aA}$ & $22,4 \mathrm{aAB}$ & $23,8 \mathrm{aA}$ & $20,4 \mathrm{bB}$ & $22,2 \mathrm{aAB}$ & $23,5 \mathrm{aA}$ & $22,7 \mathrm{a}$ \\
\hline $\mathrm{NHI}-40$ & & $24,2 \mathrm{aB}$ & $16,6 \mathrm{bC}$ & $24,9 \mathrm{aB}$ & $28,3 \mathrm{aA}$ & $16,0 \mathrm{bCD}$ & $14,0 \mathrm{cD}$ & $20,7 \mathrm{~b}$ \\
\hline Média & & $17,6 \mathrm{~B}$ & $13,6 \mathrm{D}$ & $20,1 \mathrm{~A}$ & $17,5 \mathrm{~B}$ & $16,0 \mathrm{C}$ & $16,4 \mathrm{C}$ & - \\
\hline Controle & \multirow{4}{*}{$5-20$} & $12,2 \mathrm{bB}$ & $14,2 \mathrm{cAB}$ & $15,3 \mathrm{bA}$ & $12,6 \mathrm{cB}$ & $13,8 \mathrm{cAB}$ & $12,5 \mathrm{cB}$ & $13,4 \mathrm{~d}$ \\
\hline $\mathrm{NO}-40$ & & $24,4 \mathrm{aAB}$ & $25,8 \mathrm{aA}$ & $23,4 \mathrm{aABC}$ & $21,4 \mathrm{aCD}$ & $22,1 \mathrm{aBC}$ & $19,0 \mathrm{bD}$ & $22,7 \mathrm{a}$ \\
\hline $\mathrm{NH}-40$ & & $24,3 \mathrm{aA}$ & $21,1 \mathrm{bBC}$ & $21,2 \mathrm{aB}$ & $18,2 \mathrm{bC}$ & $17,5 \mathrm{bC}$ & $22,6 \mathrm{aAB}$ & $20,8 \mathrm{~b}$ \\
\hline NHI - 40 & & $24,4 \mathrm{aA}$ & $15,3 \mathrm{cC}$ & $18,0 \mathrm{bB}$ & $16,3 \mathrm{bBC}$ & $16,2 \mathrm{abBC}$ & $16,3 \mathrm{bBC}$ & $17,8 \mathrm{c}$ \\
\hline \multirow[t]{2}{*}{ Média } & & $21,3 \mathrm{~A}$ & $19,1 \mathrm{~B}$ & $19,5 \mathrm{~B}$ & $17,1 \mathrm{C}$ & $17,4 \mathrm{C}$ & $17,6 \mathrm{C}$ & - \\
\hline & \multirow{5}{*}{$0-5$} & & & & $-28 D A E$ & & & \\
\hline Controle & & $12,6 \mathrm{cC}$ & $12,3 \mathrm{bC}$ & $16,0 \mathrm{bB}$ & $17,4 \mathrm{~dB}$ & $22,7 \mathrm{aA}$ & $15,4 \mathrm{bB}$ & $16,1 \mathrm{c}$ \\
\hline $\mathrm{NO}-40$ & & $15,4 \mathrm{bD}$ & $15,3 \mathrm{aD}$ & $21,9 \mathrm{aA}$ & $20,3 \mathrm{cAB}$ & $17,2 \mathrm{cCD}$ & $18,9 \mathrm{aBC}$ & $18,2 \mathrm{~b}$ \\
\hline $\mathrm{NH}-40$ & & $20,7 \mathrm{aBC}$ & $17,0 \mathrm{aD}$ & $22,9 \mathrm{aB}$ & $23,2 \mathrm{bA}$ & $18,9 \mathrm{bcCD}$ & $21,0 \mathrm{aBC}$ & $20,6 \mathrm{a}$ \\
\hline NHI - 40 & & $20,5 \mathrm{aB}$ & $15,1 \mathrm{aC}$ & $23,6 \mathrm{aA}$ & $25,7 \mathrm{aA}$ & $20,5 \mathrm{abB}$ & $19,2 \mathrm{aB}$ & $20,8 \mathrm{a}$ \\
\hline Média & & $17,3 \mathrm{D}$ & $14,9 \mathrm{E}$ & $21,1 \mathrm{AB}$ & $21,7 \mathrm{~A}$ & $19,8 \mathrm{BC}$ & $18,6 \mathrm{CD}$ & - \\
\hline Controle & \multirow{4}{*}{$5-20$} & $15,7 \mathrm{cD}$ & $16,6 \mathrm{cCD}$ & $22,9 \mathrm{bA}$ & $16,6 \mathrm{bCD}$ & $21,8 \mathrm{aAB}$ & $18,8 \mathrm{bBC}$ & $18,7 \mathrm{c}$ \\
\hline NO - 40 & & $19,7 \mathrm{bBC}$ & $19,3 \mathrm{bcC}$ & $21,1 \mathrm{bABC}$ & $21,9 \mathrm{aABC}$ & $22,4 \mathrm{aAB}$ & $23,6 \mathrm{aA}$ & $21,3 \mathrm{~b}$ \\
\hline $\mathrm{NH}-40$ & & $22,3 \mathrm{abC}$ & $21,3 \mathrm{abC}$ & $31,5 \mathrm{aA}$ & $22,1 \mathrm{aC}$ & $23,0 \mathrm{aAB}$ & $25,4 \mathrm{aB}$ & $24,3 \mathrm{a}$ \\
\hline NHI - 40 & & $23,2 \mathrm{aA}$ & $23,4 \mathrm{aA}$ & $24,0 \mathrm{bA}$ & $22,7 \mathrm{aA}$ & $24,0 \mathrm{aA}$ & $23,9 \mathrm{aA}$ & $23,5 \mathrm{a}$ \\
\hline \multirow[t]{2}{*}{ Média } & & $20,2 \mathrm{C}$ & $20,2 \mathrm{C}$ & $24,9 \mathrm{~A}$ & $20,8 \mathrm{BC}$ & $22,8 \mathrm{AB}$ & $22,9 \mathrm{AB}$ & - \\
\hline & \multirow{8}{*}{$0-5$} & & & & $-42 D A E$ & & & \\
\hline Controle & & $15,7 \mathrm{ABC}$ & $13,6 \mathrm{cC}$ & $16,9 \mathrm{cAB}$ & $17,2 \mathrm{dA}$ & $15,7 \mathrm{dABC}$ & $14,1 \mathrm{dBC}$ & $15,5 \mathrm{e}$ \\
\hline $\mathrm{NO}-40+40$ & & $19,6 \mathrm{cA}$ & $15,8 \mathrm{cB}$ & $17,4 \mathrm{cAB}$ & $18,0 \mathrm{dAB}$ & $16,0 \mathrm{~dB}$ & $15,2 \mathrm{~dB}$ & $17,0 \mathrm{de}$ \\
\hline $\mathrm{NO}-00+80$ & & $19,6 \mathrm{cB}$ & $13,3 \mathrm{cC}$ & $16,0 \mathrm{cC}$ & $20,0 \mathrm{cdB}$ & $15,2 \mathrm{dC}$ & $26,9 \mathrm{bA}$ & $18,5 \mathrm{~cd}$ \\
\hline $\mathrm{NH}-40+40$ & & $14,8 \mathrm{eB}$ & $21,1 \mathrm{bA}$ & $20,7 \mathrm{bA}$ & $21,4 \mathrm{cA}$ & $22,3 \mathrm{cA}$ & $20,8 \mathrm{cA}$ & $20,2 \mathrm{c}$ \\
\hline $\mathrm{NH}-00+80$ & & $18,1 \mathrm{cdD}$ & $28,8 \mathrm{aA}$ & $21,5 \mathrm{bC}$ & $30,3 \mathrm{aA}$ & $28,3 \mathrm{bAB}$ & $25,5 \mathrm{bB}$ & $25,4 \mathrm{~b}$ \\
\hline $\mathrm{NHI}-40+40$ & & $24,4 \mathrm{bB}$ & $30,0 \mathrm{aA}$ & $21,0 \mathrm{bC}$ & $24,6 \mathrm{bB}$ & $21,6 \mathrm{cBC}$ & $24,0 \mathrm{aBC}$ & $24,3 \mathrm{~b}$ \\
\hline NHI $-00+80$ & & $29,0 \mathrm{aC}$ & $28,4 \mathrm{aC}$ & $29,8 \mathrm{aBC}$ & $28,1 \mathrm{aC}$ & $32,0 \mathrm{aAB}$ & $33,5 \mathrm{aA}$ & $30,1 \mathrm{a}$ \\
\hline Média & & $20,2 \mathrm{~B}$ & $21,6 \mathrm{AB}$ & $20,5 \mathrm{~B}$ & $22,8 \mathrm{~A}$ & $21,6 \mathrm{AB}$ & $22,9 \mathrm{~A}$ & - \\
\hline Controle & \multirow{8}{*}{$5-20$} & $15,3 \mathrm{bAB}$ & $13,4 \mathrm{cB}$ & $16,0 \mathrm{cAB}$ & $16,3 \mathrm{cAB}$ & $18,6 \mathrm{aA}$ & $16,3 \mathrm{bAB}$ & $16,0 \mathrm{~d}$ \\
\hline $\mathrm{NO}-40+40$ & & $14,7 \mathrm{bC}$ & $16,3 \mathrm{cC}$ & $17,5 \mathrm{bcBC}$ & $20,6 \mathrm{bAB}$ & $21,7 \mathrm{aA}$ & $18,0 \mathrm{abABC}$ & $18,1 \mathrm{~d}$ \\
\hline $\mathrm{NO}-00+80$ & & $22,8 \mathrm{aAB}$ & $25,0 \mathrm{bA}$ & $21,0 \mathrm{bB}$ & $22,2 \mathrm{bAB}$ & $20,3 \mathrm{aBC}$ & $16,8 \mathrm{bC}$ & $21,4 \mathrm{~cd}$ \\
\hline $\mathrm{NH}-40+40$ & & $17,6 \mathrm{bC}$ & $23,8 \mathrm{bA}$ & 20,4 bABC & $21,8 \mathrm{bAB}$ & $20,7 \mathrm{aABC}$ & $18,7 \mathrm{abBC}$ & $20,5 \mathrm{c}$ \\
\hline $\mathrm{NH}-00+80$ & & $22,8 \mathrm{aBC}$ & $31,5 \mathrm{aA}$ & $25,8 \mathrm{aB}$ & $23,0 \mathrm{abBC}$ & $21,6 \mathrm{aC}$ & $19,6 \mathrm{abC}$ & $24,1 \mathrm{a}$ \\
\hline $\mathrm{NHI}-40+40$ & & $22,0 \mathrm{aAB}$ & $23,1 \mathrm{bAB}$ & $25,7 \mathrm{aB}$ & $24,0 \mathrm{abAB}$ & $20,8 \mathrm{aBC}$ & $18,2 \mathrm{abC}$ & $22,3 \mathrm{abc}$ \\
\hline NHI $-00+80$ & & 23,4 aABC & $22,1 \mathrm{bBC}$ & $25,6 \mathrm{aAB}$ & $26,5 \mathrm{aA}$ & $21,1 \mathrm{aC}$ & $21,1 \mathrm{aC}$ & $23,3 \mathrm{ab}$ \\
\hline Média & & $19,8 \mathrm{BC}$ & $22,2 \mathrm{~A}$ & $21,7 \mathrm{AB}$ & $22,1 \mathrm{~A}$ & $20,7 \mathrm{AB}$ & $18,4 \mathrm{C}$ & - \\
\hline
\end{tabular}

das por fatores não medidos no presente trabalho. A redução nos teores de nitrato, em relação à fonte sem inibidor, para aquelas plantas foi de $26 \%, 28 \%$ e $40 \%$, respectivamente (Tabela 3 ).

$\mathrm{Na}$ camada de 5-20 cm, os maiores teores de nitrato foram observados para a fonte nítrica (Tabela 3). Este resultado é indicativo de que, devido à aplicação da fonte nítrica, houve maior lixiviação do $\mathrm{N}$, observando-se valores de nitrato de $14,5 \mathrm{mg} \mathrm{kg}^{-1}$, na camada de $0-5 \mathrm{~cm}$, e $22,7 \mathrm{mg} \mathrm{kg}^{-1}$, na camada de $5-20 \mathrm{~cm}$. Com relação às plantas de cobertura, verificaram-se menores teores de nitrato no solo nas parcelas com C. spectabilis, em relação a quase todas as fontes de $\mathrm{N}$, o que pode ter ocorrido 
devido à menor produção de massa de matéria seca por esta leguminosa. Segundo Aita et al. (2007), a nitrificação é influenciada pela quantidade de biomassa produzida. Estes mesmos autores observaram que as taxas líquidas de nitrificação, em SPD, foram maiores sob os resíduos culturais de aveia/milho do que sob pousio/milho.

Aos $28 \mathrm{DAE}$, o teor de $\mathrm{NO}_{3}^{-}$foi influenciado pelas plantas de cobertura e pelo manejo da adubação nitrogenada (Tabela 3 ). As alterações mais importantes foram observadas para o controle, cujos valores foram inferiores, em relação às formas de manejo do $\mathrm{N}$, principalmente na camada de $0-5 \mathrm{~cm}$, quando a planta de cobertura foi a crotalária, o que pode ter sido reflexo da não aplicação do $\mathrm{N}$ e por ser esta uma espécie leguminosa. Observou-se, também, que, nestas duas profundidades, as fontes amoniacais proporcionaram os maiores teores de nitrato (Tabela 3 ). Isto pode ter decorrido do fato de $\mathrm{o} \mathrm{NH}_{4}^{+}$servir de substrato para as bactérias nitrificantes. Crusciol et al. (2011), Pacheco et al. (2011) e Nascente et al. (2012) também observaram aumentos nos teores de nitrato no solo, devido à aplicação de amônio. Além disto, aplicações de fontes nítricas podem ter favorecido a lixiviação do nitrato, por possuírem menores teores do que as fontes amoniacais.

No desdobramento da interação de plantas de cobertura, dentro de cada forma de manejo do N, constatou-se que houve diferenças para os teores de nitrato (Tabela 3). Os menores teores de nitrato foram observados onde se cultivou C. spectabilis, como ocorreu nas avaliações aos 14 DAE.

Nas avaliações realizadas aos 42 DAE, na camada de $0-5 \mathrm{~cm}$, os maiores teores de nitrato ocorreram com a aplicação de $80 \mathrm{~kg} \mathrm{ha}^{-1}$ de $\mathrm{N}$ na forma amoniacal com inibidor, diferindo dos demais tratamentos (Tabela 3). Este resultado indica a falta de efeito do inibidor, porém, quando se observa o alto teor de amônio no solo, quando utilizada esta forma de manejo, é natural supor que uma maior proporção tenha sido nitrificada. Marcelino (2009) observou que, aos 30 dias após a adição de DCD em ureia, houve inibição de $53 \%$, em relação ao tratamento sem DCD.

O nitrato pode, também, ser lixiviado no solo, caso ocorram chuvas intensas, como no primeiro mês deste experimento (mais de $80 \mathrm{~mm}$ ) (Figura 1), corroborando outros resultados de pesquisa (Justino et al. 2006, Crusciol et al. 2011, Nascente et al. 2012).
$\mathrm{Na}$ camada de 5-20 cm, as fontes $\mathrm{NH}-00+80$, $\mathrm{NHI}-40+40$ e NHI - $00+80$ foram as que proporcionaram os maiores teores de nitrato, não diferindo entre si (Tabela 3). A aplicação de $80 \mathrm{~kg} \mathrm{ha}^{-1}$ de $\mathrm{N}$ na forma amoniacal resultou nos maiores teores de amônio (Tabela 1), portanto, era esperado que, para esta fonte, o teor de nitrato também fosse maior, como, de fato, ocorreu. Crusciol et al. (2011) observaram aumentos nos teores de nitrato no solo após a aplicação de ureia. Aita et al. (2007) também observaram que a nitrificação aumentou com a quantidade de $\mathrm{N}$ amoniacal aplicada. Vale destacar que, nas duas profundidades, os teores de nitrato no solo, no tratamento controle, foram os menores.

Os teores de amônio no solo (Tabela 2) foram semelhantes aos de nitrato (Tabela 3 ), o que não seria comum, tratando-se de solos aeróbicos, onde o processo de nitrificação acontece rapidamente (Crusciol et al. 2011). Isto pode ter ocorrido devido ao fato de o solo já estar por 6 anos em SPD, apresentando altos teores de matéria orgânica $\left(34 \mathrm{~g} \mathrm{dm}^{-3}\right)$ e favorecendo a contínua liberação de amônio para o solo. Segundo Sá (1999), os solos com SPD já consolidado, acima de 5 anos, proporcionam maior mineralização da matéria orgânica, o que pode contribuir para o aumento nos teores de amônio no solo.

Por sua vez, os valores de $\mathrm{pH}$ foram baixos (Tabela 1), o que pode afetar o processo de nitrificação do amônio. De acordo com Chung \& Zasoski (1993), a atividade das bactérias nitrificantes é fortemente influenciada pela acidez do solo, sendo reduzida em $\mathrm{pH}$ inferior a 6,0, como observado neste experimento.

Crusciol et al. (2011) observaram aumento da nitrificação, quando o $\mathrm{pH}$ foi superior a 6,0 . Isto demonstra que o manejo da adubação nitrogenada e o uso de plantas de cobertura são ferramentas que podem ser utilizadas para alterar os níveis de nitrato e amônio no solo, como já relatado por Nascente et al. (2012).

Maiores teores de amônio no solo podem ser importantes para várias culturas, como o arroz, que se desenvolve melhor em solos com teores equivalentes de amônio e nitrato (Holzschuh et al. 2009). A absorção de nitrogênio como amônio é mais vantajosa para a planta, uma vez que a assimilação de $\mathrm{N}$ é um processo altamente exigente, em termos de energia, requerendo a transferência de dois elétrons por molécula de $\mathrm{NO}_{3}{ }^{-}$convertido em $\mathrm{NO}_{2}{ }^{--}$e mais seis elétrons por molécula de $\mathrm{NO}_{2}^{--}$convertido em 
$\mathrm{NH}_{4}^{+}$e, por outro lado, dois elétrons e uma molécula de ATP por molécula de $\mathrm{NH}_{4}^{+}$convertida em glutamato (Malavolta 1980). Assim, a assimilação do $\mathrm{NO}_{3}{ }^{-}$demanda mais energia, em comparação ao $\mathrm{NH}_{4}^{+}$(Bredemeier \& Mundstock 2000).

\section{CONCLUSÕES}

1. O uso do inibidor de nitrificação (dicianodiamida - DCD) e o cultivo de Crotalaria spectabilis proporcionaram maiores teores de amônio no solo.

2. A aplicação da fonte amoniacal sem inibidor de nitrificação em dose total $\left(80 \mathrm{~kg} \mathrm{ha}^{-1}\right.$ de sulfato de amônio), aos 30 DAE, e com inibidor (tanto parcelada quanto em dose única) proporcionaram os maiores teores de nitrato no solo.

\section{AGRADECIMENTOS}

À Fundação de Apoio à Pesquisa do Estado de São Paulo (FAPESP), pelo apoio financeiro, e ao Conselho Nacional de Desenvolvimento Científico e Tecnológico (CNPq), pelo prêmio de excelência em pesquisa, concedido ao segundo e quarto autores.

\section{REFERÊNCIAS}

AITA, C. et al. Nitrificação do nitrogênio amoniacal de dejetos líquidos de suínos em solo sob sistema de plantio direto. Pesquisa Agropecuária Brasileira, Brasília, DF, v. 42, n. 1, p. 95-102, 2007.

ARANDA, V. et al. Effect of soil type and management (organic vs. conventional) on soil organic matter quality in olive groves in a semi-arid environment in Sierra Mágina Natural Park (Spain). Geoderma, Amsterdam, v. 164, n. 1-2, p. 54-63, 2011.

BREDEMEIER, C.; MUNDSTOCK, C. M. Regulação da absorção e assimilação do nitrogênio nas plantas. Ciência Rural, Santa Maria, v. 30, n. 2, p. 365-372, 2000.

CANTARELLA, H.; FURLANI, P. R. Arroz de sequeiro. In: RAIJ, B. V. et al. (Coords.). Recomendações de adubação e calagem para o Estado de São Paulo. 2. ed. Campinas: Instituto Agronômico/Fundação IAC, 1996. p. 48-49.

CARVALHO, A. M. et al. Cover plants with potential use for crop-livestock integrated systems in the Cerrado region. Pesquisa Agropecuária Brasileira, Brasília, DF, v. 46, n. 10, p. 1200-1205, 2011.

CHUNG, J. B.; ZASOSKI, R. J. Effect of high ammonium levels on nitrification, soil acidification, and exchangeable cation dynamics. Communication in Soil Science and Plant Analysis, New York, v. 24, n. 17-18, p. 2123- 2135, 1993.

CONEGLIAN, C.; MORAES, M. H. Efeito de resíduos vegetais de milheto (Peninisetum americanum) e da calagem em algumas propriedades físicas e químicas de um Nitossolo Vermelho em sistema de semeadura direta. Irriga, Botucatu, v. 11, n. 3, p. 293-304, 2006.

CRUSCIOL, C. A. C. et al. Nitrate role in basic cation leaching under no-till. Revista Brasileira de Ciência do Solo, Viçosa, v. 35, n. 6, p. 1975-1984, 2011.

D'ANDRÉA, A. F. et al. Carbon and nitrogen storage, and inorganic nitrogen forms in a soil under different management systems. Pesquisa Agropecuária Brasileira, Brasília, DF, v. 39, n. 2, p. 179-186, 2004.

DI, H. J.; CAMERON, K. C. Nitrate leaching in temperate agroecosystems: sources, factors and mitigating strategies. Nutrient Cycling in Agroecosystems, Dordrecht, v. 64, n. 3, p. 237-256, 2002.

FAGERIA, N. K. et al. Growth and mineral nutrition of field crops. Boca Raton: CRC Press, 2011.

FRYE, W. W. et al. Dicyandiamide as a nitrification inhibitor in crop production in the southeastern USA. Communication in Soil Science and Plant Analysis, New York, v. 20, n. 19-20, p. 1969-1999, 1989.

GUIMARÃES, G. L. et al. Culturas de inverno e pousio na sucessão da cultura da soja em plantio direto. Acta Scientiarum Agronomy, Maringá, v. 25, n. 2, p. 339-344, 2003.

HOLZSCHUH, M. J. et al. Rice growth as affected by combined ammonium and nitrate supply. Revista Brasileira de Ciência do Solo, Viçosa, v. 33, n. 5, p. 13231331, 2009.

JUSTINO, G. C. et al. Absorção e redução de nitrato em duas cultivares de arroz na presença de alumínio. Pesquisa Agropecuária Brasileira, Brasília, DF, v. 41, n. 8, p. 1285 1290, 2006.

KLUTHCOUSKI, J. et al. Manejo do solo e o rendimento de soja, milho, feijão e arroz em plantio direto. Scientia Agricola, Piracicaba, v. 57, n. 1, p. 97-104, 2000.

MALAVOLTA, E. Elementos de nutrição mineral de plantas. São Paulo: Agronômica Ceres, 1980.

MARCELINO, R. Inibidor de nitrificação em fertilizantes nitrogenados e rendimento de milho. 2009. 81 f. Dissertação (Mestrado em Gestão de Recursos Agroambientais) Instituto Agronômico de Campinas, Campinas, 2009.

MORETI, D. et al. Atributos químicos de um Latossolo Vermelho sob diferentes sistemas de preparo, adubações e plantas de cobertura. Revista Brasileira de Ciência do Solo, Viçosa, v. 31, n. 1, p. 167-175, 2007. 
NASCENTE, A. S. et al. Produtividade do arroz de terras altas em função do manejo do solo e da época de aplicação de nitrogênio. Pesquisa Agropecuária Tropical, Goiânia, v. 41, n. 1, p. 60-65, 2011.

NASCENTE, A. S. et al. Ammonium and nitrate in soil and upland rice yield as affected by cover crops and their desiccation time. Pesquisa Agropecuária Brasileira, Brasília, DF, v. 47, n. 12, p. 1699-1706, 2012.

NASCENTE, A. S. et al. Cover crop termination timing on rice crop production in a no-till system. Crop Science, Madison, v. 53, n. 6, p. 2659-2669, 2013 d.

NASCENTE, A. S.; CRUSCIOL, C. A. C. Cover crops and herbicide timing management on soybean yield under notillage system. Pesquisa Agropecuária Brasileira, Brasília, DF, v. 47, n. 2, p. 187-192, 2012.

NASCENTE, A. S.; CRUSCIOL, C. A. C. Cover crops affecting levels of ammonium and nitrate in the soil and upland rice development. Semina: Ciências Agrárias, Londrina, v. 34, n. 5, p. 2189-2202, 2013 c.

NASCENTE, A. S.; CRUSCIOL, C. A. C.; COBUCCI, T. The no-tillage system and cover crops: alternatives to increase upland rice yields. European Journal of Agronomy, Amsterdam, v. 45, n. 1, p. 124-131, 2013 b.

NASCENTE, A. S.; LI, Y.; CRUSCIOL, C. A. C. Cover crops and no-till effects on physical fractions of soil organic matter. Soil and Tillage Research, Amsterdam, v. 130 , n. 1 , p. $52-57,2013$ a.
PACHECO, L. P. et al. Produção e ciclagem de nutrientes por plantas de cobertura nas culturas de arroz de terras altas e de soja. Revista Brasileira de Ciência do Solo, Viçosa, v. 35, n. 5, p. 1787-1800, 2011.

SÁ, J. C. M. Manejo da fertilidade do solo no sistema plantio direto. In: SIQUEIRA, J. O. et al. (Eds.). Interrelação fertilidade, biologia do solo e nutrição de plantas. Viçosa: UFLa/DCS, 1999. p. 267-319.

SILVA, E. C. et al. Utilização do nitrogênio da palha de milho e de adubos verdes pela cultura do milho. Revista Brasileira de Ciência do Solo, Viçosa, v. 32, n. esp., p. 2853-2861, 2008.

SILVA, F. C. Manual de análises químicas de solos, plantas e fertilizantes. Rio de Janeiro: Embrapa Solos, 1999.

SUBBARAO, G. V. et al. Biological nitrification inhibition (BNI): is it a widespread phenomenon? Plant and Soil, Dordrecht, v. 294, n. 1-2, p. 5-18, 2007.

SUBBARAO, G. V. et al. Evidence for biological nitrification inhibition in Brachiaria pastures. Proceedings of the National Academy of Sciences, Washington, DC, v. 106, n. 41, p. 17302-17307, 2009.

TRENKEL, M. E. Improving fertilizer use efficiency: controlled-release and stabilized fertilizers in agriculture. Paris: IFIA, 1997. 